http://dx.doi.org/10.35381/racji.v6i1.1412

\title{
La acción de protección en el Ecuador
}

\section{Protection action in Ecuador}

\author{
Julio César-de-Jesús Arrias-Añez \\ uq.julioarrias@uniandes.edu.ec \\ Universidad Regional Autónoma de los Andes, Quevedo \\ Ecuador \\ https://orcid.org/0000-0001-5259-9359 \\ Orlando Iván Ronquillo-Riera \\ uq.orlandoronquillo@uniandes.edu.ec \\ Universidad Regional Autónoma de los Andes, Quevedo \\ Ecuador \\ https://orcid.org/0000-0001-6020-7255 \\ Damaris Abigail Domínguez-Vargas \\ dq.damarisadv28@uniandes.edu.ec \\ Universidad Regional Autónoma de los Andes, Quevedo \\ Ecuador \\ https://orcid.org/0000-0003-0274-7151
}

Recepción: 15 de marzo 2021

Revisado: 25 de mayo 2021

Aprobación: 15 de junio 2021

Publicación: 01 de Julio 2021 


\section{Estimado Editor (a):}

La acción de protección tiene el propósito de salvaguardar los derechos de las personas frente a una vulneración, sin embargo, las personas toman ventaja de esta garantía creando así un abuso del derecho al momento de presentar la demanda de acción de protección en casos que no están establecidos en las normas jurídicas indicadas para el efecto. Para Rodríguez Santos, Narváez Zurita, Vázquez Calle y Erazo Álvarez (2020) plantean que:

Para requerir de la justicia constitucional, interponiendo una acción de protección, solo se requiere la calidad de ciudadano, por lo tanto, la puede presentar cualquier persona en el momento en que sus derechos hayan sido violentados ya sea por una autoridad pública o por personas privadas; se pretende alcanzar un restablecimiento al estado anterior de la vulneración del derecho y una subsecuente reparación por el daño causado. (p.608)

En tal sentido, muchas veces los profesionales del derecho hacen caso omiso a lo dispuesto en la norma jurídica y por buscar una salida fácil del caso interponen una acción de protección aun cuando existe un procedimiento específico para el caso, aunque claro está el tiempo de duración de los casos no constitucionales van a tener un tiempo de duración más extenso a comparación de la acción de protección. Es por esta razón que la acción de protección necesariamente debe pasar por una especie de filtro con la finalidad de que procedan los casos necesarios y que no haya la innecesaria carga laboral. Sin embargo, para Castro Montero y Llanos Escobar (2015) esbozan:

Ahora bien, según la normativa vigente, se puede proponer AP en contra de actuaciones administrativas no judiciales emitidas por autoridades competentes, prestadores de servicios públicos, personas del ámbito privado, políticas públicas; $y$, en general, en contra de cualquier acto discriminatorio ejecutado por cualquier persona. $(p-12)$

Por lo tanto, para proponer una acción en contra de actos violatorios de derechos constitucionales, el sistema de justicia es el encargado de brindar una solución satisfactoria en la cual se puedan resarcir los daños producidos por actos violatorios, de igual manera, tienen la facultad de verificar su procedencia y por ende evitar el 
abuso del derecho. Por ello, Castro Pizarro, Masache Romero y Durán Ocampo (2019) manifiestan que:

El Derecho Público es la doctrina regulatoria de la asimetría existente en las relaciones de poder entre el gobierno y la sociedad. Lo que se explica por ser el gobierno el único organismo que ejerce autoridad en la toma de decisiones sobre los derechos de los ciudadanos, las que deben estar reguladas por la Ley. (p.351)

Así mismo, es necesario la implementación de un mecanismo de control referente a las demandas de acción de protección interpuestas, a pesar de que existan requisitos para utilizar este recurso, los abogados hacen caso omiso y proponen esta acción aun cuando no es necesario hacerlo, ya que existe un procedimiento específico para procesos ordinarios. Para interponer la debida demanda de acción de protección obligatoriamente tiene que cumplir con los elementos necesarios para que se constituyan la violación de derechos constitucionales y que la única vía para cesar la vulneración de estos derechos sea la acción de protección. Esta acción se caracteriza por ser un proceso rápido además de proteger los derechos establecidos en la Carta Magna.

Continuando con los planteamientos, se indica que, de acuerdo a lo establecido en la ley, se define, describen el objeto de la acción de protección, en el siguiente cuadro se detalla el contenido y su obligatoriedad.

\section{Cuadro 1.}

Normativa Legal.

\begin{tabular}{|l|l|}
\hline \multicolumn{1}{|c|}{ Normativa vigente } & \multicolumn{1}{|c|}{ Aplicación } \\
\hline Ley Orgánica de Garantías Jurisdiccionales & Artículo 39.- Objeto. - La acción de \\
y Control Constitucional(2009) & protección tendrá por objeto el amparo \\
directo y eficaz de los derechos \\
reconocidos en la Constitución y tratados \\
internacionales sobre derechos humanos, \\
& que no estén amparados por las acciones \\
de hábeas corpus, acceso a la información \\
pública, hábeas data, por incumplimiento, \\
extraordinaria de protección y \\
extraordinaria de protección contra \\
decisiones de la justicia indígena.
\end{tabular}


Artículo 40.- Requisitos. - La acción de protección se podrá presentar cuando concurran los siguientes requisitos:

1. Violación de un derecho constitucional; 2. Acción u omisión de autoridad pública o de un particular de conformidad con el artículo siguiente; $y$,

3. Inexistencia de otro mecanismo de defensa judicial adecuado y eficaz para proteger el derecho violado.

Artículo 41.- Procedencia y legitimación pasiva. La acción de protección procede contra:

1. Todo acto u omisión de una autoridad pública no judicial que viole o haya violado los derechos, que menoscabe, disminuya o anule su goce o ejercicio.

2. Toda política pública, nacional o local, que conlleve la privación del goce 0 ejercicio de los derechos y garantías.

3. Todo acto u omisión del prestador de servicio público que viole los derechos y garantías.

4. Todo acto u omisión de personas naturales o jurídicas del sector privado, cuando ocurra al menos una de las siguientes circunstancias:

a) Presten servicios públicos impropios o de interés público;

b) Presten servicios públicos por delegación o concesión;

c) Provoque daño grave;

d) La persona afectada se encuentre en estado de subordinación o indefensión frente a un poder económico, social, cultural, religioso o de cualquier otro tipo.

5. Todo acto discriminatorio cometido por cualquier persona.

Artículo 42.- Improcedencia de la acción. La acción de protección de derechos no procede:

1. Cuando de los hechos no se desprenda que existe una violación de derechos constitucionales.

2. Cuando los actos hayan sido revocados o extinguidos, salvo que de tales actos se deriven daños susceptibles de reparación.

3. Cuando en la demanda exclusivamente se impugne la constitucionalidad 0 


\begin{tabular}{|l|l|}
\hline & legalidad del acto u omisión, que no \\
conlleven la violación de derechos. \\
4. Cuando el acto administrativo pueda ser \\
impugnado en la vía judicial, salvo que se \\
demuestre que la vía no fuere adecuada ni \\
eficaz. \\
5. Cuando la pretensión del accionante sea \\
la declaración de un derecho. \\
6. Cuando se trate de providencias \\
judiciales. \\
7. Cuando el acto u omisión emane del \\
Consejo Nacional Electoral y pueda ser \\
impugnado ante el Tribunal Contencioso \\
Electoral.
\end{tabular}

Elaboración: Los autores (2021).

A pesar de que en la Ley de Garantías Jurisdiccionales y Control Constitucional constan los requisitos para presentar la acción de protección, así como su procedencia siguen existiendo la falta de control al momento de interponer una demanda, es decir, no existe un "filtro formal" que acepte las acciones de protección exclusivamente en los casos establecidos por el Estatuto. Al respecto, Ortiz Rivera (2015) señala:

La Corte Suprema de Justicia ecuatoriana, en su momento señaló que el Amparo no era un recurso común por inconstitucionalidad, sino una medida protectora de carácter especial, cuya admisibilidad está limitada en primer lugar a los casos en que el acto de autoridad es violatorio de alguno de los derechos reconocidos por la Constitución a las personas. (p.24)

De las fundamentaciones teóricas y la pronunciación de la Corte Constitucional del Ecuador respecto al tema, la acción de protección procederá solo cuando exista una vulneración real de derechos constitucionales, más no como una medida alternativa que se utiliza para finalizar una causa de manera instantánea. La acción de protección tiene la finalidad de cesar o resarcir el daño causado por la violación de derechos constituciones, se caracteriza por ser un procedimiento ágil y eficaz, pues, la audiencia se realiza máximo en 48 horas, esto con la finalidad de evitar continuar con la violación del derecho o bien repararlo de manera inmediata, en cuanto al legitimado pasivo de esta acción no solo es en contra de autoridad pública no judicial también recae a personas particulares que hayan amenazado o violado un derecho constitucional. El 
Ecuador adoptó esta medida con el propósito de que las personas ejerzan su derecho cuando se sientan amenazados además de garantizar la seguridad jurídica en el país. Se destaca lo planteado por Arichavala Zúñiga, Narváez Zurita, Guerra Coronel y Erazo Álvarez (2020):

Son múltiples las razones que han impulsado el estudio de la acción de protección, existen importantes análisis e investigaciones, a pesar de ello, es necesario examinar la inminente necesidad de arribar hacia un verdadero Estado Constitucional de derechos y justicia por medio de la constitucionalización del derecho. (p.164)

Es necesario la creación de medidas al momento de admitir una demanda de acción de protección, puesto que, con los requisitos que existen hoy en día no son totalmente eficaces ya que de igual forma se interponen un sinnúmero de demandas por esta acción que conlleva a la innecesaria carga laboral y al abuso del derecho.

\section{FINANCIAMIENTO}

No monetario.

\section{AGRADECIMIENTO}

A la Universidad Regional Autónoma de los Andes, Ecuador, por motivar el desarrollo de la Investigación.

\section{REFERENCIAS CONSULTADAS}

Arichavala Zúñiga, J.; Narváez Zurita, C.; Guerra Coronel, M. y Erazo Álvarez, J. (2020). La acción de protección: ¿Una vía idónea para tutelares derechos constitucionales? [Action of protection: ¿An ideal way to protect rights?]. Iustitia Socialis, 5(8), 162-186. http://dx.doi.org/10.35381/racji.v5i8.567

Asamblea Nacional (2008). Ley Orgánica de Garantías Jurisdiccionales y Control Constitucional. [Organic Law on Jurisdictional Guarantees and Constitutional Control]. Segundo Suplemento del Registro Oficial No.52, 22 de octubre 2009. Recuperado de: https://n9.cl/kqdip 
Castro Montero, J. y Llanos Escobar, L. (2015) La Acción de Protección como mecanismo de garantía de los derechos: configuración institucional, práctica y resultados en la ciudad de Quito. [The Protection Action as a mechanism to guarantee rights: institutional configuration, practice and results in the city of Quito]. VIII Congreso Latinoamericano de Ciencia Política. Asociación Latinoamericana de Ciencia Política. Pontificia Universidad Católica del Perú. Recuperado de: https://n9.cl/ptzkn

Castro Pizarro, J., Masache Romero, C., y Durán Ocampo, A. (2019). La aplicación del Derecho Público en el Ecuador. [The application of Public Law in Ecuador]. Revista Universidad y Sociedad, 11(4), 350-360. Recuperado de: https://n9.cl/zu1u

Ortiz Rivera, R. (2015). El mal uso de la acción de protección en el Ecuador. [The misuse of protection action in Ecuador]. Tesis. Para optar al Título de Abogada. Universidad Nacional de Loja. Recuperado de: https://n9.cl/0zwk8

Rodríguez Santos, P.; Narváez Zurita, C.; Vázquez Calle, J.; Erazo Álvarez, J. (2020) Importancia de la acción de protección en el modelo constitucional de derechos $y$ justicia. [Gravitation of the Protection Action in the constitutional model of rights and justice] lustitia Socialis, 5(1),604-619. Recuperado de: http://dx.doi.org/10.35381/racji.v5i1.632 